\title{
When Multiple Disasters Strike: Louisiana Fishers in the Aftermath of Hurricanes and the British Petroleum Deepwater Horizon Oil Spill
}

\author{
Bethany A. Lyon \\ Louisiana State University at Baton Rouge \\ Pamela F. Nezat \\ Louisiana State University at Baton Rouge \\ Katie E. Cherry \\ Louisiana State University at Baton Rouge \\ Loren D. Marks \\ Bollghw \\ Part of the Other Social and Behavioral Sciences Commons
}

\section{Original Publication Citation}

*Lyon, B. A., Nezat, P. F., Cherry, K. E., \& Marks, L. D. (2015). When multiple disasters strike:

Louisiana fishers in the aftermath of hurricanes and the British Petroleum Deepwater Horizon Oil Spill. In K. E. Cherry (ed.), Traumatic stress and long-term recovery: Coping with disasters and other negative life events (pp. 57-70). New York: Springer.

\section{BYU ScholarsArchive Citation}

Lyon, Bethany A.; Nezat, Pamela F.; Cherry, Katie E.; and Marks, Loren D., "When Multiple Disasters Strike: Louisiana Fishers in the Aftermath of Hurricanes and the British Petroleum Deepwater Horizon Oil Spill" (2015). Faculty Publications. 4862.

https://scholarsarchive.byu.edu/facpub/4862

This Book Chapter is brought to you for free and open access by BYU ScholarsArchive. It has been accepted for inclusion in Faculty Publications by an authorized administrator of BYU ScholarsArchive. For more information, please contact ellen_amatangelo@byu.edu. 


\title{
Chapter 4 \\ When Multiple Disasters Strike: Louisiana \\ Fishers in the Aftermath of Hurricanes and the British Petroleum Deepwater Horizon Oil Spill
}

\author{
Bethany A. Lyon, Pamela F. Nezat, Katie E. Cherry and Loren D. Marks
}

\section{Introduction}

The 2010 Deepwater Horizon oil spill devastated the US Gulf Coast, particularly Louisiana, Mississippi, Alabama, and Florida. Many coastal residents, especially commercial fishers, were directly impacted by the approximately 200 million gallons $^{1}$ of oil that spilled into the Gulf Coast. Years after the spill, lasting effects to the coastal communities can still be seen. Louisiana Gulf Coast fishers and their families offer a prototypical example of cumulative adversity, given that Hurricanes Katrina and Rita ravaged this same region in 2005, followed by severe Hurricanes Gustav and Ike in 2008. Given the paucity of research on both natural and technological disaster exposure, individuals and families who have weathered storms and are striving to endure the uncertainties of the BP oil spill have unique insights to offer on cumulative adversity during a historically difficult period of time and circumstance. Our objective in this chapter is to capture and express the fears and

${ }^{1}$ There are 42 gallons in a barrel of oil, placing the British Petroleum (BP) oil spill at roughly 5 million barrels. Spill estimates range from 185 to 205 million gallons of oil.

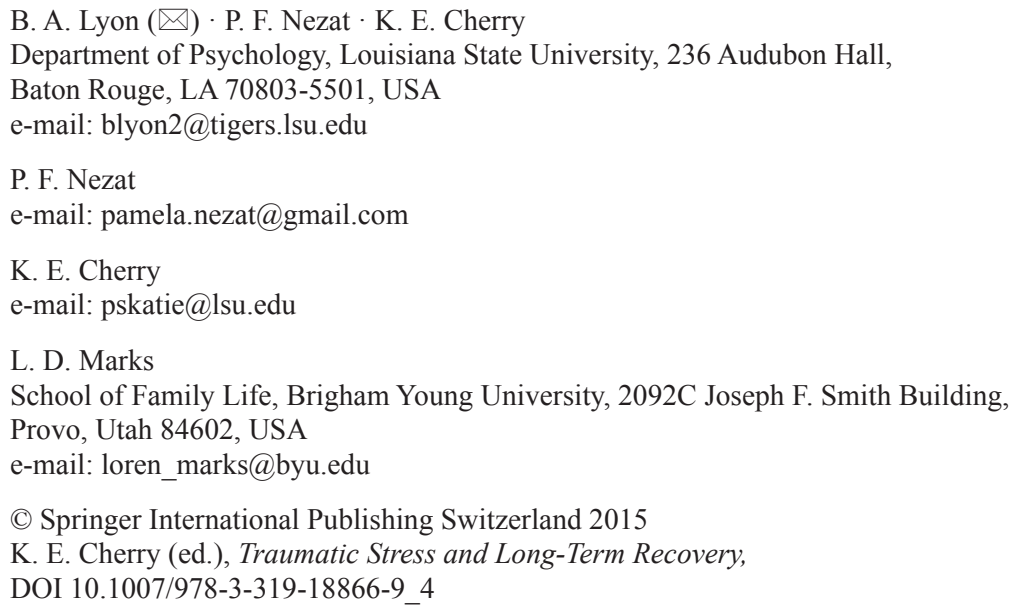


concerns faced by commercial fishers and to convey the resilience exemplified by many of the individuals and families who shared their experience with us during structured interviews conducted at least 12 months after the BP oil spill.

\section{Overview of Literature}

In the paragraphs that follow, we briefly review previous studies that span three catastrophic oil spills: the North Sea oil rig disaster, the Exxon Valdez oil spill, and early findings from the BP Deepwater Horizon oil spill. We then turn our attention to the concept of cumulative adversity and a closely related notion, the pileup of demands that impact family stress and adaptation in the wake of multiple stressors.

\section{The 1980 North Sea Oil Rig Disaster}

The 1980 North Sea oil rig disaster occurred between the United Kingdom and Norway. One of the rig legs broke and the entire oil rig capsized due to poor weather conditions. Of the 212 men on board, only 89 survived the disaster (Holgersen, Klöckner, Boe, Weisæth \& Holen, 2011). Holgersen et al. (2011) carried out a longitudinal study focused on long-term mental health after the oil rig disaster, testing participants in 1980, 1981, 1985, and 2007. Based on analyses of participants' symptoms of post-traumatic stress disorder (PTSD), four symptom trajectories were revealed: resilient, recovery, chronic, or relapse. The largest group was the resilient group $(n=43)$, which had diminishing PTSD scores after the disaster - and in many cases reduced to a score of zero after just a few years. The recovery group $(n=10)$ showed a gradual decline in PTSD symptoms across the 27-year span. The chronic group $(n=8)$ showed essentially no reduction in symptoms across time, and the relapse group $(n=9)$ followed the initial gradual reduction of symptoms in the first few months post disaster, but then experienced a gradual increase in symptoms over the course of the next 27 years. These trajectories and typologies convey widely differential adjustment patterns across individuals experiencing the same disaster. Additional research is needed to help determine (and perhaps predict) which people impacted by a disaster are most at risk for falling into one of the latter, more negatively impacted and less resilient groups.

\section{The 1989 Exxon Valdez Oil Spill}

The Exxon Valdez supertanker disaster on March 24, 1989, on Bligh Reef in Prince William Sound, Alaska was (at the time) the worst oil spill in the US history. Many studies document long-term threats to mental health in commercial fishers affected by the Exxon Valdez oil spill. For instance, Palinkas, Petterson, Russell, and Downs 
(1993) tested participants in 13 Alaskan communities affected by the Exxon Valdez oil spill 1 year after the disaster occurred. The researchers determined that participants who were highly exposed to the oil spill (those who resided in coastal areas) had higher rates of mental health problems than those from a community further from the disaster area. Arata, Picou, Johnson, and McNally (2000) also studied commercial fishers 6 years after the Exxon Valdez oil spill. Their findings indicated that those who suffered economic loss after the spill showed higher levels of depression, PTSD, and anxiety than those who did not experience economic losses.

\section{Comparisons Between the Exxon Valdez and BP Deepwater Horizon Oil Spills}

The Exxon Valdez findings, which document profound and lasting harm for those whose livelihood depends on natural resources, provide historical precedent for understanding the current circumstances of the US Gulf Coast fishers (including shrimpers and oystermen) affected by the BP Deepwater Horizon spill. Gill, Picou, and Ritchie (2012) reported a direct comparison between the Exxon Valdez disaster and the BP Deepwater Horizon oil spill for the mental and social health of people directly affected by the spills 5 months after these events. High stress levels were found in both groups of participants, with the strongest predictors of high stress levels being family health concerns, commercial ties to the renewable resources, [uncertain] economic future, economic loss, and exposure to the oil.

\section{The 2010 BP Deepwater Horizon Oil Spill}

The 2010 BP Deepwater Horizon oil spill was reported to be the worst spill this continent has ever seen, with estimates of 200 million gallons of oil that poured into the Gulf of Mexico (Gill et al., 2012). The spill has been devastating to the commercial fishing and seafood industries. The long-term impacts of an oil spill of this magnitude on the environment and the industries tied to the environment are still undetermined. When an event of an unprecedented scale occurs, experts have no direct point of reference. Some researchers have looked to previous oil spills in order to extrapolate and to establish some hypothetical expectations to relieve the uncertainty felt by coastal residents, as well as anticipating the environmental implications, but this is not an easy charge. It is, of course, a more attainable goal to estimate damage done versus predicting future effects.

Indeed, there is evidence pertaining to the immediate psychosocial impacts of the 2010 BP Deepwater Horizon oil spill. For instance, Grattan et al. (2011) compared coastal community residents directly impacted by the oil to those who were indirectly impacted but found no differences in psychological distress between the two groups. Differences in mental health were found, however, between those who faced economic loss and those that did not, with those experiencing economic loss 
also experiencing psychological impacts after the disaster, consistent with the Arata et al. (2000) findings from the Exxon Valdez spill.

Lee and Blanchard (2012) surveyed coastal residents to assess community attachment, negative affective states, including anxiety and fear, and other sociodemographic characteristics while the oil from the BP spill was still flowing (June 2010). Analyses of the full sample (935 households) and subsequent analyses aggregated by household type (family member employed in the oil industry; fishing/ seafood industry; no involvement in either industry) indicated that greater attachment to their community of residence was associated with higher levels of psychological distress. This finding was surprising in that community attachment has been widely recognized as having a beneficial effect on community resilience and well-being. Lee and Blanchard's (2012) findings imply that the salutary effects of community attachment may not hold in crisis conditions immediately after a technological disaster. The authors also suggested that a high level of community attachment may have made residents less likely to leave even though they were living in a social atmosphere full of stress, worry, and negative affect. In a follow-up investigation, Cope, Slack, Blanchard, and Lee (2013) reported additional survey data collected in the same geographic region using different household samples tested at two later intervals: wave 2 (4 months out from baseline, October 2010) and wave 3 (1 year from the explosion date, April 2011). Cope et al. found that physical and mental health effects were worse at wave 1 baseline assessment when the spill was still flowing compared to waves 2 and 3 , implying that uncertainty is a major factor in post-disaster distress. They also found that stronger community attachment was associated with reduced psychological distress in the later waves of testing overall. For fishing households, however, significant interaction effects with the time of testing variable indicated that the negative mental health impacts at wave 1 remained evident at waves 2 and 3, suggesting that fishers may be uniquely vulnerable to distress associated with the BP oil spill 1 year later (see Cherry et al., 2015 , for related discussion). Interpretative caution is warranted, because different household samples were compared across the three waves of testing. Nonetheless, Cope et al.'s results highlight the complex relationship one's stress level has with the community they are surrounded by, which also appear to vary over time for coastal community residents directly impacted by technological disaster.

\section{Cumulative Adversity and the "Pileup" of Demands}

As documented in the existing literature, dealing with traumatic life events can be difficult and trying: but multiple traumas, especially within a narrow time frame, can have devastating effects, particularly if a second trauma occurs before the victim has recovered from the first one (Marks, Nesteruk, Hopkins-Williams, Swanson, \& Davis, 2006). In the 5 years preceding the BP Deepwater Horizon oil spill, Gulf Coast residents had been forced to navigate their way through the aftermath of four major Hurricanes (Katrina, Rita, Gustav, and Ike). Mental health becomes a 
prevalent concern when individuals, families, and communities face so much adversity, particularly in such a compressed period of time. Mong, Niguchi, and Ladner (2012) tested Gulf Coast residents for PTSD and their use of coping strategies, 1-2 months after the BP spill was stopped. Mong and colleagues found that $28 \%$ of their sample showed significant levels of PTSD symptoms. Further, negative coping strategies were positively correlated with PTSD symptoms for the participants directly affected by the oil spill. These results could be due in part to the immediate time frame of the study, in which the participants are still in a type of aftershock. Positive coping strategies, however, were negatively correlated with PTSD symptoms. Mong and colleagues stressed the importance of studying potential long-term impacts of the oil spill to learn more (regarding both positive and negative coping).

Keinan, Shrira, and Shmotkin (2012) examined lifetime cumulative adversity faced by middle-age Israelis. Their findings suggest the more trauma an individual faces, the higher the level of distress. However, those who experienced two or less adverse life events also reported lower well-being (as gauged by quality of life and optimism/hope) than those who experienced three adverse life events. The authors suggested that cumulative adversity may activate both positive and negative effect, in distress and well-being. The authors also note that their index of cumulative adversity does not gauge duration or severity of the traumatic event, which are likely critical variables to consider.

Seery et al. (2010) have also studied cumulative adversity through the course of one's life and resilience against the negative outcomes associated with those events. Their findings show that mental health and well-being were the highest for those that reported some adversity, compared to those that report none as well as those that report the higher levels of adversity. The average number of adverse life events (i.e., bereavement, loved one's illness, relationship stress, violent events, social stress, personal illness, and disasters) experienced by participants was 7.69 events. Participants who had lived through a small number of traumatic life experiences exhibited lower scores of distress, less functional impairment, fewer symptoms of PTSD, and higher life satisfaction. Those who have been through more than the average number of traumatic experiences showed a reversal of these findings, with higher marks on the negative outcomes and lower satisfaction with life, revealing a U-shaped curved function with relation to the number of adverse events.

As implicitly noted in our brief overview of research related to catastrophic oil spills, psychological trauma, and cumulative adversity, the extant literature primarily contains findings based on psychometrically sound measures yielding strictly quantitative data. The current chapter's findings are based on qualitative data derived from in-depth interviews and participants' responses to open-ended questions. Qualitative research allows for a unique opportunity to highlight what the participants consider important and can allow them to elaborate their thoughts, feelings, and concerns in a much more detailed manner than a closed response paper and pencil measure (Marks \& Dollahite, 2011). 


\section{Method}

\section{Participants}

In all, 64 commercial fishers and their family members were tested $(M$ age $=54.7$ years, $S D=15.7$; age range $=21-90$ years; 34 men and 30 women). They were enrolled in a research program on post-Katrina resilience described more fully elsewhere (see Cherry et al., 2015). All had experienced catastrophic losses in the 2005 Hurricanes Katrina and Rita and were directly affected by the 2010 BP oil spill. They were recruited from multiple sources in St. Bernard and Plaquemines parishes (counties) and through a mailing to the United Commercial Fishermen's Association (UCFA).

\section{Procedure, Coding, and Analyses}

Participants were interviewed in their homes or in a community location across two (or more) sessions, separated by at least a week. The procedures used in this study were reviewed and approved by the Institutional Review Board of Louisiana State University in Baton Rouge, LA. All participants were assigned a three-digit number (301-364) to preserve anonymity, as referenced throughout this chapter. A more complete description of the method is provided in Chap. 12 (this volume). In this chapter, we focus on participants' responses to one multifaceted, open-ended question:

Have you been directly affected by the recent oil spill in the Gulf Coast? If so, in what way?

Please tell us how the oil spill has affected you, your family and your community.

Of the 64 participants, four couples responded to this question jointly and one participant declined for a total of 59 completed open-ended responses (digitally recorded and transcribed verbatim). Narrative data were then content analyzed in a manner consistent with grounded theory methodology (Strauss \& Corbin, 1998). One coding team of four members (one graduate student, three undergraduate students) met weekly during the fall semester of 2013 to carry out the open coding process (see Chap. 12, this volume, for description). Each week the coders discussed the prevalent ideas and themes covered in the 10-12 interviews coded that week, until all 61 interviews had been coded.

\section{Findings}

In all, seven core themes were identified in these data. Given the richness of these data, many of the salient issues and themes evident in our participants' narratives will require additional attention in future work. In this chapter, we have limited 
ourselves to three of the most central and pervasive themes that emerged from our interviews with Louisiana Gulf Coast fishers, shrimpers, and oystermen. These themes work together to present a textured picture of the lived experience of the participants' over the past decade.

Theme 1: Troubled Present, Uncertain Future conveys the uncertainty fishers felt regarding how the spill would play out over time, and what would become of their fishing careers and lifestyles. The water provides a way of life for these fishers, and those interviewed expressed belief that the BP oil spill threatened to strip them of their livelihood. Theme 2: Environmental Devastation reflects the fishers' profound concerns with changes that have already occurred in the environment. Theme 3: The "Pileup" Effect after a Decade of Disasters captures the fishers' reports regarding recent catastrophic hurricanes as sources of accumulated anguish over the past decade. To the degree possible, we provide firsthand accounts and primary data from the participants themselves. Direct quotations and narratives are offered to support and illustrate each of the themes, respectively.

\section{Theme 1: Troubled Present, Uncertain Future}

Uncertainty of the extent of damage and how the Deepwater Horizon oil spill would impact the lifestyle of commercial fishers was a major theme addressed in many of the interviews. Not knowing how and when the effects of the oil spill would be resolved was a serious source of stress and worry for those interviewed. The fishers' almost haunting reality is that no one knows exactly how much damage the oil spill has caused or what the long-term fallout will be. This was, and is, very unsettling for the fishers and their families - as well as for other Gulf Coast residents who fish and enjoy the water recreationally. A 52-year-old male explained that:

326: [The Deepwater Horizon oil spill] could possibly be more devastating than what Katrina was to us. I knew after Katrina that one day, as far as...the fishing industry...that everything would be fine. But as I told you the first day, that nobody knows what the effects of this is.

For many of the participants, fishing was their sole source of income, and the oil spill threatened to take that away from them. The uncertainty fishers and their families face was captured by a 50 -year-old woman:

318: It is unnerving. It is stressful because this is what [my husband] has done all his life, and it is uncertain. There is uncertainty of the future.

As the following participants note, fishing means far more to them than an occupation, or even a career; it is a way of life. The catching and harvesting of fish, shrimp, and oysters are not only an economic base, they are also part of the cultural heritage of lifelong coastal residents in south Louisiana. The more mature generation of fishers feel responsible for this heritage - and for the next generation (see Chap. 18, this volume, for related discussion). The thought of this heritage, livelihood, and life fading is devastating to some, as illustrated by the following interview excerpts. 
313: It is more than just a job. You feel like if we are the generation that loses this, then we are responsible for losing our heritage (47-year-old male).

301: At my age it isn't going to affect me that bad, but the younger people who want to be fishermen, who are fishermen, it's going to affect them for years and years and years to come. It may even be the end of their way of life (77-year old male).

330: It is definitely going to be a thing of the past. After this generation, I do not think they will have any more commercial fishermen. I think it will just be in history books after this (43-year old female).

Not everyone felt pessimism weighing them down, however. One wife of a coastal fisherman said,

316: I guess I wasn't afraid of the outcome [or worried about] if we could survive it. I knew we could. Maybe not doing what he was going to-you know, fishing, but we would survive and I was confident that...that the Gulf would take care of it. I mean I prayed, I prayed about it. And everybody else prayed about it. It was just the uncertainty (51-year old female).

Even for the more optimistic, like 316, the uncertainty of how bad this disaster will be for them in both loss of their heritage and livelihood seemed uncomfortable at best and terrifying at worst.

320: I'm not sure what to do right now...I see it coming to an end really, really fast here. And...I'm just...really kind of scared. I mean, it costs a lot of money to live...(48-year-old male).

However, uncertain the fishers and their spouses were about their own livelihood, every related report indicated that this man-made disaster was going to be hard on the environment. As one participant summarized:

325: Mother Nature can destroy something and build it back, but like with the oil spill, we never had an oil spill before and we do not know what is going to [happen. It could] be a long, long-term [disaster] (60-year old male).

The environmental effects noted by the commercial fishermen interviewed are covered in the second major theme, which we turn to next.

\section{Theme 2: Environmental Devastation}

The second theme addresses the environmental effects of the oil spill. After five million barrels (about 200 million gallons) of oil gushed into the Gulf of Mexico, the ecosystems of the sea and coastline took a catastrophic hit. Fishermen witnessed and continue to see these devastations first hand. And while the full extent of the damage remains unknown, some environmental effects witnessed by the participants were heartbreaking to them, as described in the next excerpts:

302: I have seen dead pelicans out there. I have seen dead turtles. I have seen all, all the catfish especially. And these catfish, I mean, big hearty catfish...this huge [shows size with hands], the whole bank for miles and miles and miles full of dead catfish (59-year old male). 
352: Our fish died, our oysters died, our crabs are deformed, our shrimp are deformed. They are born with no eyes. We have shrimp with no eyes. Yes, we have crabs with holes in the shells. We have oysters with pits in them from bacteria. It has never been seen before. We have things that we see that have never been seen before. We have shrimp that are growing [in deformed ways].... When you do this type of work and you sell bait, shrimp mainly... you got a product that cannot be sold. You are out of business (46-year old male).

A great number of the fishers spoke of a chemical agent used in the clean-up efforts called the dispersant. Dispersant changes the properties of the oil, both chemically and physically, in order to change the potentially hazardous effects of surface oil slicks (National Research Council, 2005, p. 10). The dispersant was developed to bind with the oil on the surface moving the dispersed oil droplets into the water column thus reducing the surface oil that would threaten the coastal wetlands. Dispersants ideally balance the risks and dangers of oil between the surface and shoreline and the underwater ecosystems in the water column and on the seafloor (National Research Council, 2005, p. 2; see National Commission on the BP Deepwater Horizon Oil Spill and Offshore Drilling, 2011 for a more detailed description of the BP Deepwater Horizon oil spill clean-up efforts). Unfortunately, the dispersant reportedly had some unforeseen complications as noted by the following participants:

310: That dispersant that they actually used all over here was not supposed to be used in sixty feet of water or less. We do not have many places in Louisiana that have sixty feet of water, so [virtually] every place it was used was illegal. And EPA told them not to, but they [did] (55-year-old male).

358: When they shoved that dispersant in there and made the oil sink, we still got oil coming up. Today. That dispersant, first good storm you get out in the Gulf's going to roll that bottom up, and that dispersant's going to wash free, and that stuff's going to come up again. You have oil all over the place again (71-year old male).

The dispersant caused problems in particular for oyster production because it killed the spat, which is essentially the juvenile stage in oyster development. Eastern oyster (Crassostrea virginica) is the most prevalent species of oyster harvested in the US Gulf Coast (Oyster Technical Task Force, 2012). The term spat is used to describe any small or immature oyster with shell length ranging from 0.3 up to $25.0 \mathrm{~mm}$, where the adult oyster shell length is classified as longer than $75 \mathrm{~mm}$ (Oyster Technical Task Force, 2012, p. 37). Oysters in the Gulf of Mexico typically reach adult size in 18-24 months, after 5-6 years oyster size could grow to $150 \mathrm{~mm}$ (Oyster Technical Task Force, 2012, p. 44). In the mobile larval stage, oysters' movement is determined primarily by water currents and salinity (Oyster Technical Task Force, 2012, p. 44). This delicate life cycle of oysters worried many of the fishers. One participant reported that the damage seemed to be:

358: From the pollution...not so much from the oil, as from the dispersant they [used]. The dispersant not only screwed up the oyster beds, but it killed all the reproduction. So there's no spats. So that means we don't know how many years that'll be before they [the oysters] start reproducing on their own (71-year old male).

Oyster fishermen also had to deal with freshwater diversions. The diversions were used to stop the Gulf water from making landfall, but these diversions threw off the delicate balance between salt water and freshwater that oysters need to thrive. 
As a result, the oyster fishing suffered great losses. The following two reports from oystermen are reflective:

347: Oysters are something...it ain't like your other seafood. It takes a long time to grow. They ran a lot of fresh water for that BP spill to try to push the oil out. And when they did that, it made the mussels grow on the oysters that were back alive (60-year old male).

360: [The oyster] resource has been severely impacted...the serious thing that we are waiting to see whether it comes back...[is] the production of oysters that we see, the resource rebound. We have not seen it yet, and that is disturbing us - disturbing the people with the state, the oystermen, the Wildlife and Fisheries, the biologists (55-year old male).

A comparatively younger participant still saw a "silver lining" to all the environmental damage caused by the oil spill (see Chap. 21, this volume, for a related discussion). He spoke of coastal erosion being a serious and long-standing issue for the Louisiana coastline, and now from his perspective, people are finally paying attention to this issue due to the attention drawn by the BP oil spill:

349: Actually it's improving it now because they are actually doing something to try to prevent coastal erosion. Since the oil spill there's been more people looking at [coastal erosion], and it's more concentrated, so it might actually help more than it does harm, in my opinion (28-year old male).

Such optimism, however, was the exception not the rule in the participants' interviews. The combination of haunting uncertainty regarding the future (Theme 1) and serious concerns about the delicate environmental balance in the Gulf and surrounding waterways seemed to be perennial stressors for many that we interviewed. The economic, psychological, and emotional blow dealt by Deepwater Horizon was not only severe - in the eyes of many, it remains a long-term if not permanent one. The blow leveled by Deepwater Horizon was not, however, the first or even the second that these hardy individuals and families have weathered. We now turn to the third and final theme, The "Pileup" Effect after a Decade of Disasters.

\section{Theme 3: The "Pileup" Effect after a Decade of Disasters}

As discussed at the outset of this chapter, the Louisiana Gulf Coast fishers and their families provide a unique and prototypical opportunity to learn about severe, cumulative adversity. The Deepwater Horizon oil spill is the newest stressor added to a long list of adversities that these individuals have faced over the last decade. These fishermen have experienced back-to-back Hurricanes Katrina and Rita in August and September of 2005, were then slammed by another set of back-to-back hurricanes (Gustav and Ike) in 2008, and were then dealt a third blow of the Deepwater Horizon oil spill in 2010.

The third theme established by the fishers' narrative text is consistent with what family stress scholars refer to as the "pileup" of demands associated with normative events and nonnormative crises that impact families over time. The "pileup" of pre- and post-crisis demands figures prominently in the double ABC-X model of family stress and adaptation (cf. Lavee, McCubbin, \& Patterson, 1985; see also 
Chap. 21, this volume). Here, we borrow the concept of "pileup" to broadly characterize post-disaster stressors such as catastrophic losses of homes and property. In addition to disaster-related material losses, we interpret "pileup" to include possibly diminished resources to cope with prior and current environmental stressors. Several of these fishers have survived hurricanes where they lost many of their material possessions, including boats, docks, and marinas. After regrouping from the catastrophic combinations of Katrina/Rita and Gustav/Ike, the respondents were faced with the adversity of the oil spill, pushing many perilously close to a breaking point. Several respondents addressed their sense of pileup or "exacerbated" cumulative stress, including the following:

310: So financially, [the oil spill] is a big deal financially and then emotionally, because you were pulling yourself out of the Katrina/Rita/Gustav era. You were digging your way out once again. And now you come up with a manmade disaster and that is what exacerbates this whole situation (55-year old male).

313: We lost our quality of life. And so soon after Katrina and Rita. It is like the double whammy (47-year old male).

340: It ruined my lifestyle. Getting compensated is not the same as not having it happen to you at all. Katrina made everybody move and now the storm's finishing us off (51-year old male).

Not only have these participants faced financial hardships, they also referenced an impact on their quality of life, now diminished relative to earlier times. Fishing used to be a comfortable life doing what they love, but for some it has turned into a source for worry and fear.

The natural and man-made disasters striking the same region in such a short window of time reportedly impacted many aspects of participants' lives. For some, everything seemed to be piling up. For one woman, when the shrimping disappeared, her household lost:

363: ...our income coming in. We could not go shrimping. I lost my job. What more could happen? Then they had the hurricane, then this [oil spill]. It kills you. Then my Momma dies and my boyfriend dies, back-to-back (51-year old female).

Another participant said of her husband:

311: ... when the kids needed him the most, he was dealing with Katrina stuff, and now [he's] dealing with the oil spill stuff (54-year old female).

One man (321) seemed to succinctly capture the sentiment of many, "Every time we started doing good, something happens" (67-year-old male). Another woman commented that is getting harder for her to stay positive about her families' career in the oyster business and explained that, for her:

324: The oil spill, just made it that much tougher to be optimistic about being an oyster fisherman or any kind of fisherman (55-year old female).

In general the fishermen of Louisiana's Gulf Coast are tough; they are a hardy and resilient crowd. Even though they have been on the receiving end of at least three major blows that can objectively be considered catastrophic, some appear to have 
hope that things will get better one day, and that they will be able to see themselves through all of the hardships. The following excerpts reflect this optimistic view:

313: You know, I still have hope that somewhere along the line things will straighten out (47-year old male).

332: Yeah, well...it's okay...what doesn't kill you makes you stronger. God doesn't give you anything you can't handle. You know, I just wish he didn't think my shoulders were as broad as they are (52-year old female).

319: $\mathrm{Bae}^{2}$, things always work out all the time, in some fashion (44-year-old female).

Time will reveal whether the fishermen of Louisiana's Gulf Coast can absorb this "third blow" of Deepwater Horizon and find their way back to their feet. This blow will likely be the final one for some, but given our firsthand opportunity to witness the remarkable resilience of many of these individuals and families, we expect that many will not only find their feet, they will once again find their sea legs.

\section{Conclusion}

The commercial fishers of south Louisiana have been hit hard by both natural and man-made disasters. The uncertainty of what will become of their future, their finances, and their lifestyle weighs heavily, causing stress years after the spill had been capped. The uncertainty spreads into the environment, as both the oil and the dispersant used have caused horrible death and detriment to the seafood crops and industry. The uncertainty and worry of those employed by the seafood industry is extremely clear in the devastating footage of Hurricane Katrina aftermath (United Commercial Fishermen's Association \& Barisich 2011), as well as the aftershock of the BP Deepwater Horizon oil spill (Stencel \& Hopkins, 2013). Each film was made shortly after the disasters wreaked havoc on the Gulf Coast. The film Dirty Energy (Stencel \& Hopkins, 2013) especially highlights the region as a unique culture in danger of losing their fishing lifestyle, potentially making commercial fishing just a cherished memory.

The present research dives firsthand into how the fishers are faring in the years after the 2005 Hurricanes Katrina and Rita, after the 2008 Hurricanes Gustav and Ike, and the 2010 BP Deepwater Horizon oil spill. The worry and fear are ever present, as well as the financial and emotional drains. The results of our study indicate that fishers are working to keep their lifestyles, family, environment, and community afloat years after the spill. The Gulf Coast has been battered with adversity. At the same time, the coast features a community of tough, hardworking individuals that have made it through turbulent and disaster-riddled times. Further research to address the long-term impacts of these disasters and the development of interventions tailored specifically toward mitigating cumulative adversity are warranted.

2 "Bae," is a slang expression similar to "Baby." (Definition of Bae, 2010) 
Acknowledgments We thank George Barisich, President of the United Commercial Fishermen's Association, for his help with recruitment and Frank Campo of Campo's Marina in Yscloskey (southeastern St. Bernard) for providing space for interviews. We also thank Ashley Cacamo, Annie Crapanzano, and Benjamin Staab for assistance with data collection and Rachel Adamek, Devon Welsch, Kristina Fitzgerald, Claire Bernacchio, and Dina Anbinder for help with data scoring. We are grateful to Sr. Mary Keefe, Huey Gonzales, Charlie Robin, Lauren Denley, John Tesvich, and Eva Vujnovich for their contribution to the research effort, and Matthew Lee, Vijay John, and John E. Supan for their assistance in exposition concerning spat and dispersants.

This research was supported by grants from the Louisiana Board of Regents and the BP Gulf of Mexico Research Initiative, Office of Research and Economic Development, Louisiana State University. This support is gratefully acknowledged.

Correspondence concerning this chapter should be addressed to Katie E. Cherry, Department of Psychology, Louisiana State University, Baton Rouge, LA 70803-5501 (e-mail: pskatie@1su.edu).

\section{References}

Arata, C. M., Picou, J. S., Johnson, G. D., \& McNally, T. S. (2000). Coping with technological disaster: An application of the conservation of resources model to the Exxon Valdez oil spill. Journal of Traumatic Stress, 13(1), 23-39.

Cherry, K. E., Sampson, L., Nezat, P. F., Cacamo, A., Marks, L. D., \& Galea, S. (2015). Long-term psychological outcomes in older adults after disaster: relationships to religiosity and social support. Aging \& Mental Health, 19(5), 430-443.

Cope, M. R., Slack, T., Blanchard, T. C., \& Lee, M. R. (2013). Does time heal all wounds? Community attachment, natural resource employment, and health impacts in the wake of the BP Deepwater Horizon disaster. Social Science Research, 42, 872-881.

Definition of Bae. (2010). http://onlineslangdictionary.com/meaning-definition-of/bae. Accessed 23 June 2014.

Gill, D. A., Picou, J. S., \& Ritchie, L. A. (2012). The Exxon Valdez and BP oil spills: A comparison of initial social and psychological impacts. American Behavioral Scientist, 56(1), 3-23.

Grattan, L. M., Roberts, S., Mahan, W. T., Jr., McLaughlin, P. K., Otwell, S., \& Morris, J. G., Jr. (2011). The early psychological impacts of the Deepwater Horizon oil spill on Florida and Alabama communities. Environmental Health Perspectives, 119(6), 838-843.

Holgersen, K. H., Klöckner, C. A., Boe, H. J., Weisæth, L., \& Holen, A. (2011). Disaster survivors in their third decade: Trajectories of initial stress responses and long-term course of mental health. Journal of Traumatic Stress, 24(3), 334-341.

Keinan, G., Shrira, A., \& Shmotkin, D. (2012). The association between cumulative adversity and mental health: Considering dose and primary focus of adversity. Quality of Life Research, 21, $1149-1158$.

Lavee, Y., McCubbin, H. I., \& Patterson, J. M. (1985). The double ABCX model of family stress and adaptation: An empirical test by analysis of structural equations with latent variables. Journal of Marriage and the Family, 47, 811-825.

Lee, M. R., \& Blanchard, T. C. (2012). Community attachment and negative affective states in the context of the BP Deepwater Horizon disaster. American Behavioral Scientist, 56(1), 24-47.

Marks, L. D., \& Dollahite, D. C. (2011). Mining the meanings from psychology of religion's correlation mountain. Journal of Psychology of Religion and Spirituality, 3, 181-193.

Marks, L. D., Swanson, M., Nesteruk, O., \& Hopkins-Williams, K. (2006). Stressors in African American marriages and families: A qualitative study. Stress, Trauma, and Crisis: An International Journal, 9, 203-225.

Mong, M. D., Noguchi, K., \& Ladner, B. (2012). Immediate psychological impact of the Deepwater Horizon oil spill: Symptoms of PTSD and coping skills. Journal of Aggression, Maltreatment, and Trauma, 21, 691-704. 
National Research Council of the National Academies. (2005). Oil spill dispersants: Efficacy and effects. Washington, D.C.: National Academies Press.

National Commission on the BP Deepwater Horizon Oil Spill and Offshore Drilling. (2011). The use of surface and subsea dispersants during the BP Deepwater Horizon oil spill. In C. A. Farrugia (Ed.), Dispersant and oil monitoring in the Deepwater Horizon spill (pp. 1-28). New York: Nova Science Publishers, Inc.

Oyster Technical Task Force. (2012). The oyster fishery of the Gulf of Mexico, United States: A fisheries management plan, 2012 revision (pp. 31-45). Ocean Springs, MS: Gulf States Marine Fisheries Commission.

Palinkas, L. A., Petterson, J. S., Russell, J., \& Downs, M. A. (1993). Community patterns of psychiatric disorders after the Exxon Valdez Oil Spill. American Journal of Psychiatry, 150(10), $1517-1523$.

Seery, M. D., Holman, E. A., \& Silver, R. C. (2010). Whatever does not kill us: Cumulative lifetime adversity, vulnerability, and resilience. Journal of Personality and Social Psychology, 99(6), 1025-1041.

Stencel, E., Hopkins B. D. (Producers), \& Hopkins, B. D. (Director). (2013). Dirty energy [Motion picture]. United States: Cinema Libre Studio.

Strauss, A., \& Corbin, J. (1998). Basics of qualitative research: Techniques and procedures for developing grounded theory. Thousand Oaks: Sage.

United Commercial Fishermen's Association (Producers), \& Barisich, G. (Producer). (2011). Post Katrina: The plight of the Gulf Coast fishermen [Motion picture]. Available from George Barisich, 3413 Don Redden Court, Baton Rouge, LA, 70802. 